Document downloaded from:

http://hdl.handle.net/10251/66303

This paper must be cited as:

Serrano Cruz, JR.; Olmeda González, PC.; Tiseira Izaguirre, AO.; García-Cuevas González, LM.; Lefebvre, A. (2013). Importance of Mechanical Losses Modeling in the Performance Prediction of Radial Turbochargers under Pulsating Flow Conditions. SAE International Journal of Engines. 6(2):1-10. doi:10.4271/2013-01-0577.

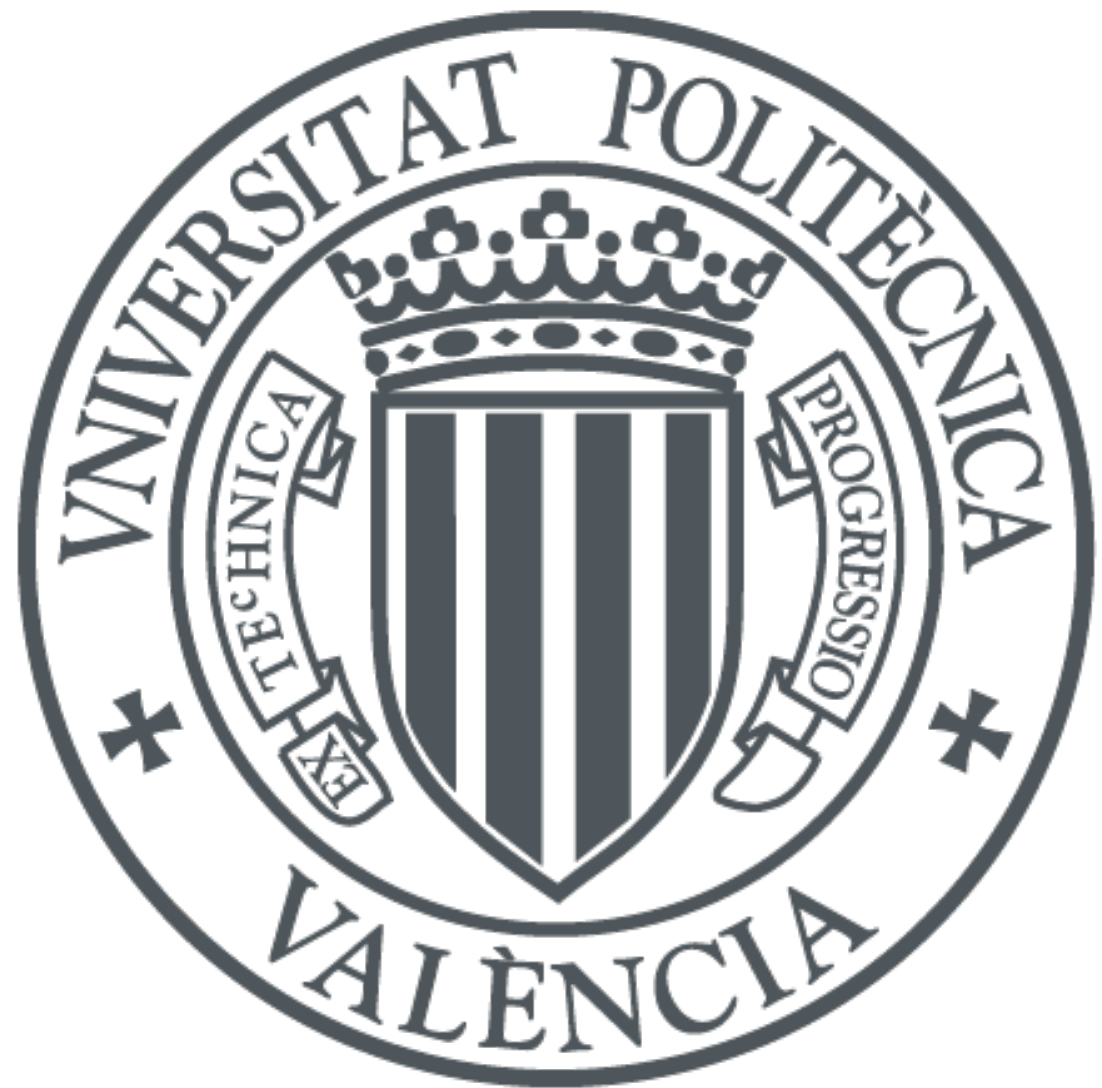

The final publication is available at

http://dx.doi.org/10.4271/2013-01-0577

Copyright SAE International

Additional Information 


\title{
Importance of mechanical losses modeling in the performance prediction of radial turbochargers under pulsating flow conditions
}

\author{
Author, co-author (Do NOT enter this information. It will be pulled from participant tab \\ in MyTechZone) \\ Affiliation (Do NOT enter this information. It will be pulled from participant tab in MyTechZone)
}

\begin{abstract}
This work presents a study to characterize and quantify the mechanical losses in small automotive turbocharging systems. An experimental methodology to obtain the losses in the power transmission between the turbine and the compressor is presented. The experimental methodology is used during a measurement campaign of three different automotive turbochargers for petrol and diesel engines with displacements ranging from $1.2 \mathrm{l}$ to $2.0 \mathrm{l}$ and the results are presented.
\end{abstract}

With this experimental data, a fast computational model is fitted and used to predict the behaviour of mechanical losses during stationary and pulsating flow conditions, showing good agreement with the experimental results. During pulsating flow conditions, the delay between compressor and turbine makes the mechanical efficiency to fluctuate. These fluctuations are shown to be critical in order to predict the turbocharger behaviour.

\section{INTRODUCTION}

Nowadays internal combustion engines, ICE, are facing with two main problems the reduction on both pollutant emissions and fuel consumption without losing their performance in order to fulfill different economical-areas' regulations like the European norm Euro VI [1].

In order to fulfill these norms, engine sizes have been reduced in recent years (downsizing) with a very high compression of the inlet air (supercharging), what is usually performed by means of a turbocharger. Engines efficiency largely depends on turbochargers efficiency.

The efficiency of a turbocharger depends on the ability to transform the energy of engine exhaust gases to mechanical

Page 1 of 10 energy in the turbine and, later on, transform this mechanical energy by compressing the fresh air in the compressor. Unfortunately, some of the mechanical energy is lost in the transmission shaft and the systems attached to it (the lubrication system, bearings, etc.) These energy losses between the turbine and the compressor are commonly called mechanical losses, which are not easy to quantify in this type of system because of both the turbochargers' small sizes and their high rotating speed [2]

Traditionally, the study of the turbochargers has been performed in medium and high loads, i.e. compression ratios above 1.5, where mechanical losses are much smaller than the rest of the energy flow in a turbocharger; but the importance of the urban cycles in the homologation of engines (where loads are very low) has led to the necessity of improving turbochargers performance in this particular operating points. In this low load cases, heat and friction losses can be very important (in some cases are even higher than the compressor mechanical power) [3], so it is very important to quantify them as properly as possible.

Theoretical studies using CFD determined the need of considering the change of the lubricating oil temperature when passing through the bearings, in view of the fact that better results were obtained that in the case of considering isothermal condition [4]. Moreover, Lihua et al. [5], studying the design of hydrostatic spindle, arrived to the conclusion of considering not only the temperature drop but also the pressure distribution of the lubricating oil across the journal in order to obtain more accurate results. Chen [6] studied the rotordynamic characteristics of large turbochargers, but no indications for small turbochargers are mentioned.

Experimental studies about mechanical losses on turbochargers are usually performed in cold tests in which the temperatures of the different fluids (oil, refrigerant and 
compressor and turbine air) are kept almost constant [7]. In this way, heat transfer effects are usually neglected and mechanical power can be determined by means of oil temperature drop. Another possibility is to use a torquemeter [8], but this approach implies the modification of the turbocharger.

Payri et al. [9] presents an empirical model in which the dependency of mechanical losses are fitted to dimensionless numbers: Reynolds, Prandtl an a dimensionless pressure difference, which expression was based on the work of Hu et al. [10], who determined that the axial thrust of the turbocharger is mostly determined by the static pressure difference of compressor impeller and the turbine's back plate, which is related to the compressor impeller outlet and turbine inlet pressure. Payri et al [9] made dimensionless the pressure difference with oil pressure later on. Podevin describes cold tests done using a torquemeter, determining that oil pressure is important due to the change on oil mass flow [8]. Deligant et al. used a torquemeter and a magnetic axial load in order to study such a load influence on friction power, being for the tested conditions up to a $12 \%$ of the friction power [12]. Finally, in Deligant's work [12] the dependency with oil pressure seems to be smaller than with oil temperature that directly affects the oil viscosity.

A physical model developed by the authors has been adjusted with experimental data obtained from a specific turbocharger test bench, in which a cold test campaign similar to that described by Payri et al. [9] was performed, so instantaneous mechanical losses can be computed.

The first part of the paper concerns about the experimental methodology and the main parameters measured to characterize mechanical losses. Then, a physical model is fitted with the experimental data and used to compute instantaneous behaviour of the turbocharger mechanical efficiency. Finally the main conclusions of the work are outlined.

\section{EXPERIMENTAL METHODOLOGY AND RESULTS}

An experimental campaign to measure several turbocharger models has been done. The experiments were done in quasiadiabatic conditions as described in [7,9], both with stationary and pulsating flow in the turbine. Pulsating flow was generated as described in the work from Serrano et al. [15].

In quasi-adiabatic tests, turbine inlet, compressor outlet and oil inlet temperatures are maintained as close as possible and the turbocharger is thermally insulated from outside. As at low and medium turbocharger speeds the temperature at the inlet of the oil needs to be low to minimize internal heat transfer between the different parts of the turbocharger, its viscosity should be similar of that found during urban driving cycles when the engine is still cold and the oil temperature is relatively low.

The turbocharger gas stand is represented schematically in figure 1 . The whole test rig has thermal insulation to minimize heat exchange with the ambient. The temperature at the inlet and the outlet of the lubrication system is measured with RTDs and the mass flow rate is measured using a Coriolis flow meter. The turbine mass flow rate is measured with a thermal mass flow meter, the temperature of the inlet and outlet flow is measured with an array of 4 type $\mathrm{K}$ thermocouples and its pressure with piezorresistive pressure transducers, as described in $[13,14]$. The compressor side is measured as the turbine. Also, the wall temperatures of the housing, the turbine and compressor casings are measured with an array of 15 type $\mathrm{K}$ thermocouples.

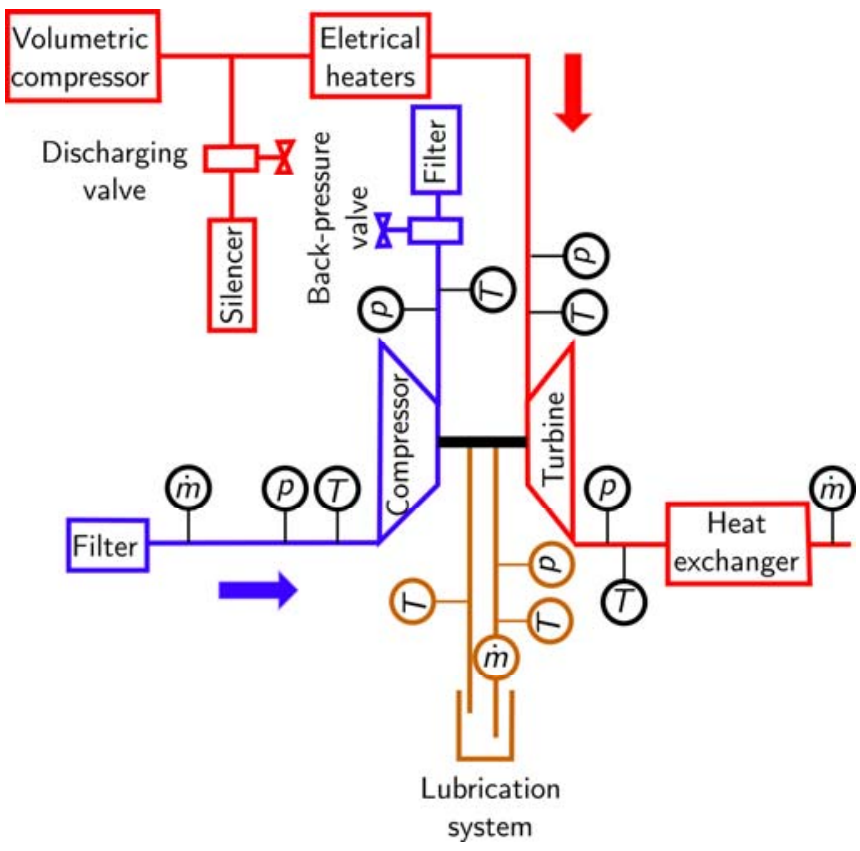

Figure 1 Turbocharger gas stand.

The first tested turbocharger has variable geometry vanes. This device is commonly used in a 2.0 liter diesel engine. It contains a water-cooling system and its bearing is composed by a plain fixed journal bearing and a separated thrust bearing. The second turbocharger is also VGT, it is used in a 1.6 liter diesel engine, it has no water-cooling system and it has a plain floating ring journal bearing and a separated thrust bearing. The third turbocharger has a waste-gate and it is used frequently in 1.2 liter petrol engines. Its housing is watercooled and its bearing system is formed by a plain floating ring journal bearing and a separated thrust bearing.

The mechanical losses are corrected due to spurious heat flow still remaining after quasi-adiabatic tests. The correction is performed as described in [12,15], so only power losses are taken into account: 


$$
\dot{W}_{\text {oil }} \approx \dot{m}_{\text {oil }} \cdot c_{\text {oil }} \cdot\left(T_{\text {oil }, \text { out }}-T_{\text {oil, in }}\right)-\dot{Q}_{\text {oil }}
$$

The mechanical efficiency is computed as:

$$
\eta_{\text {mech }} \approx 1-\frac{\dot{W}_{\text {oil }}}{\dot{W}_{t}}
$$

Power losses, mechanical efficiency and heat transfer to the oil are plotted against turbine power in figures 2, 3 and 4 for all three tested turbochargers.

The mean measured temperatures during the quasi-adiabatic tests are shown in the tables 1, 2 and 3, which show the mean inlet temperature of the oil used during the quasi-adiabatic tests for each tested turbocharger speed, as well as the mean temperature difference between the oil and turbine inlet temperatures and the oil inlet and the compressor outlet temperatures. The differences tend to be small in order to fulfill the quasi-adiabatic requirements

\begin{tabular}{|r|c|c|c|}
\hline$n$ & $T_{\text {oil,in }}$ & $\left|\left(T_{\text {oil ,in }}-T_{t, \text { in }}\right)_{\text {mean }}\right|$ & $\left|\left(T_{\text {oil ,in }}-T_{c, \text { out }}\right)_{\text {mean }}\right|$ \\
\hline$[\mathrm{rpm}]$ & {$\left[{ }^{\circ} \mathrm{C}\right]$} & {$\left[{ }^{\circ} \mathrm{C}\right]$} & {$\left[{ }^{\circ} \mathrm{C}\right]$} \\
\hline 30000 & 26.7 & 2.4 & 1.6 \\
\hline 50000 & 32.6 & 3.3 & 0.3 \\
\hline 70000 & 43.9 & 2.5 & 1.1 \\
\hline 90000 & 60.0 & 3.1 & 1.7 \\
\hline 110000 & 76.1 & 1.3 & 0.6 \\
\hline 130000 & 96.5 & 1.1 & 1.5 \\
\hline 150000 & 124.3 & 0.3 & 3.7 \\
\hline 170000 & 144.1 & 1.5 & 12.6 \\
\hline
\end{tabular}

Table 1. First turbocharge temperatures.

\begin{tabular}{|c|c|c|c|}
\hline$n$ & $T_{\text {oil,in }}$ & $\left|\left(T_{\text {oil,in }}-T_{t, \text { in }}\right)_{\text {mean }}\right|$ & $\left|\left(T_{\text {oil,in }}-T_{c, \text { out }}\right)_{\text {mean }}\right|$ \\
\hline 30000 & 23.9 & 4.9 & 3.1 \\
\hline 50000 & 25.6 & 0.8 & 0.2 \\
\hline 70000 & 37.1 & 4.3 & 1.7 \\
\hline 90000 & 48.1 & 1.0 & 0.6 \\
\hline 110000 & 70.6 & 0.7 & 9.0 \\
\hline 130000 & 84.6 & 1.5 & 1.7 \\
\hline 150000 & 105.9 & 2.0 & 3.1 \\
\hline 170000 & 127.0 & 1.4 & 3.6 \\
\hline
\end{tabular}

Table 2. Second turbocharge temperatures.

\begin{tabular}{|r|c|c|c|}
\hline$n$ & $T_{\text {oil ,in }}$ & $\left|\left(T_{\text {oil ,in }}-T_{t, \text { in }}\right)_{\text {mean }}\right|$ & $\left|\left(T_{\text {oil,in }}-T_{c, \text { out }}\right)_{\text {mean }}\right|$ \\
\hline 50000 & 32.5 & 4.1 & 1.4 \\
\hline 70000 & 41.0 & 4.3 & 1.0 \\
\hline 90000 & 49.1 & 3.0 & 0.1 \\
\hline 110000 & 61.2 & 2.6 & 1.56 \\
\hline 130000 & 72.1 & 0.6 & 2.0 \\
\hline 150000 & 89.2 & 1.8 & 5.0 \\
\hline 170000 & 112.8 & 0.6 & 0.3 \\
\hline 190000 & 130.2 & 3.3 & 3.0 \\
\hline
\end{tabular}

Table 3. Third turbocharger temperatures.

As can be seen in figures 2 to 4 , the mechanical efficiency becomes appreciably small in the quasi-adiabatic case for low turbine power. The oil inlet temperature is small and its viscosity is higher than in normal operating conditions. Nevertheless, during urban driving cycles the oil inlet temperature can be even smaller [9].

As seen in figures 2, 3 and 4, the heat transfer to the oil, even in quasi-adiabatic conditions, is an important fraction of the power losses in the lubrication system, and it is expected that its importance grows as the turbine temperature rises. These results shows that the heat exchange between the lubrication system and the rest of the turbocharger should not be neglected to compute the real power dissipated in the bearings. Figure 4 shows the bigger effects of heat transfer due to the fact that the second turbocharger is just oil-cooled.

\section{MODEL RESULTS}

A model of turbocharger bearings developed by the authors of the present work is fitted with a random subset of $10 \%$ of the whole stationary experimental database and used with OpenWAM [17,18] to simulate all the tested operating conditions, giving the results shown in figures 5 to 7 . The losses in the transmission of power between the turbine and the compressor are computed as:

$\dot{W}_{o i l}=\left[2 \cdot k_{j b} \cdot R_{j b}^{3} \cdot \frac{L_{j b}}{h_{j b}}+k_{t b} \cdot\left(R_{t b, \text { max }}^{2}-R_{t b, \text { min }}^{2}\right) \cdot \frac{R_{t b, \text { mean }}}{h_{t b}}\right] \cdot \pi \cdot \mu \cdot n^{2}$

where the oil film thickness in the thrust bearing $h_{t b}$ is computed using the following expression:

$$
h_{t b}=\left[\frac{\rho\left|k_{A_{c}} \cdot A_{c} \frac{p_{c, \text { out }}-p_{c, \text { out }}}{4}-k_{A_{t}} \cdot A_{t} \frac{p_{t, b}-p_{t, \text { out }}}{2}\right|}{6 \cdot k_{\text {trac }} \cdot n \text { s. }_{\text {oil }} \cdot G \cdot \mu}\right]^{1 / 3}
$$

In equations 3 and 4 , the 5 terms $k_{i}$ are the coefficients to adjust the model and the rest of the parameters are defined by 
the geometry of the bearings and the operating conditions. The model is described in [19].
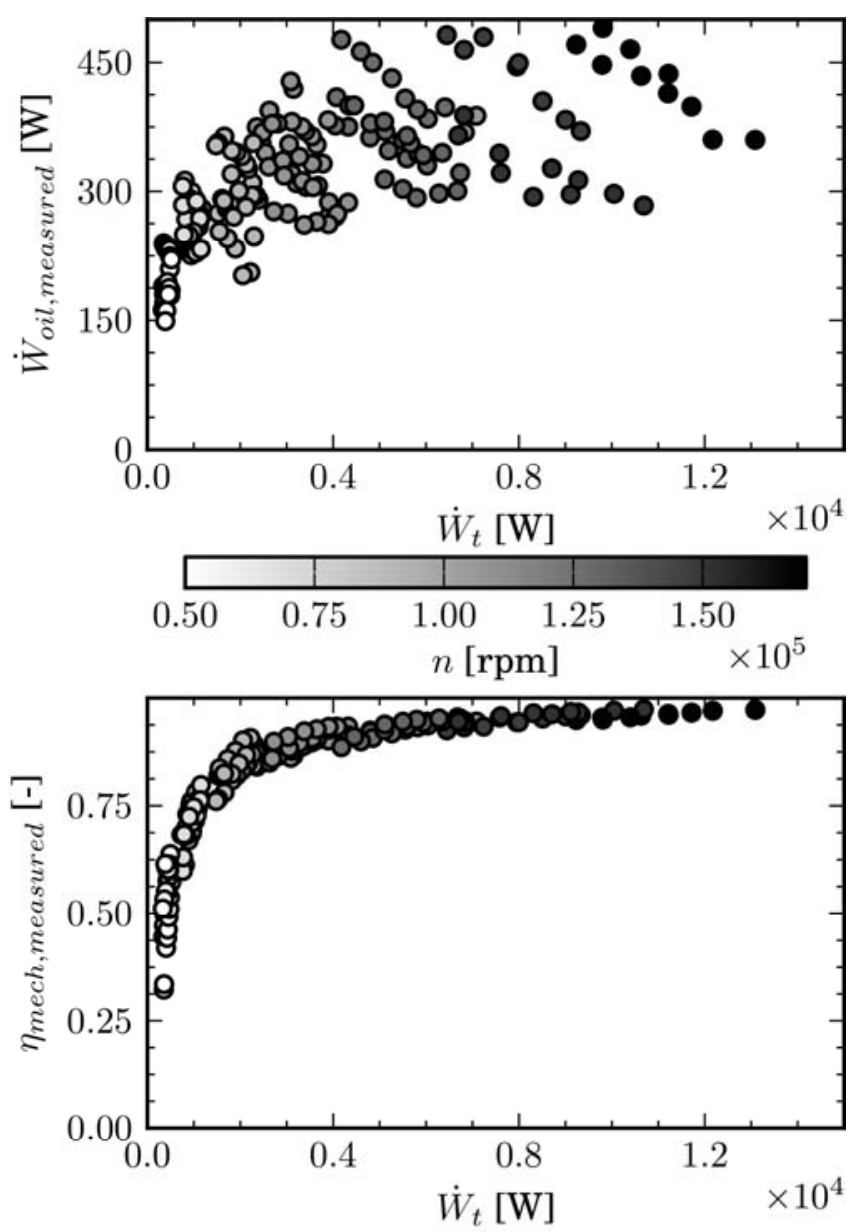

$\begin{array}{lllll}0.50 & 0.75 & 1.00 & 1.25 & 1.50\end{array}$

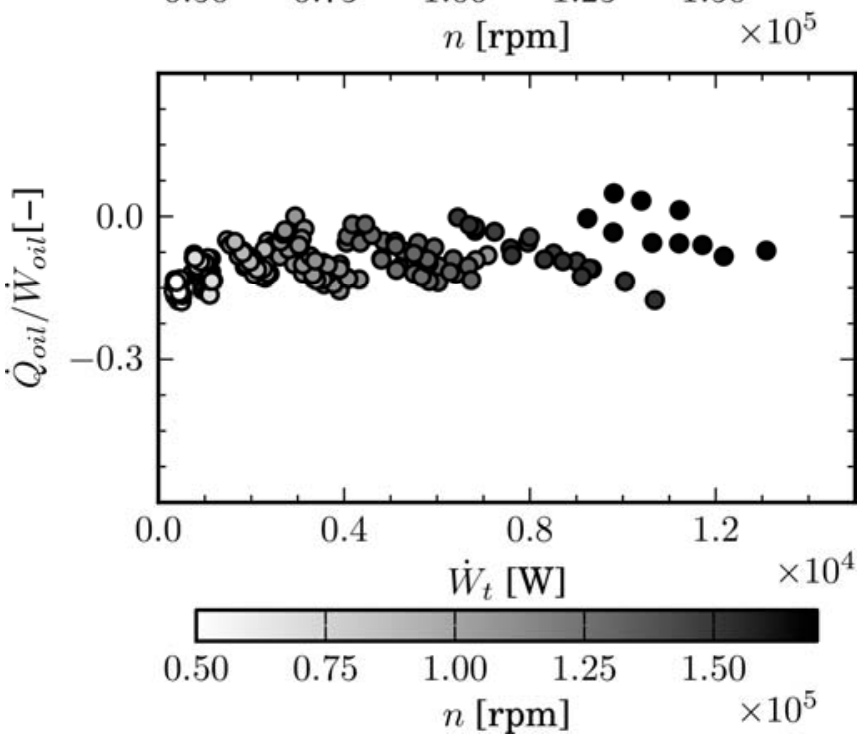

Figure 2. First turbocharger,experimental results.
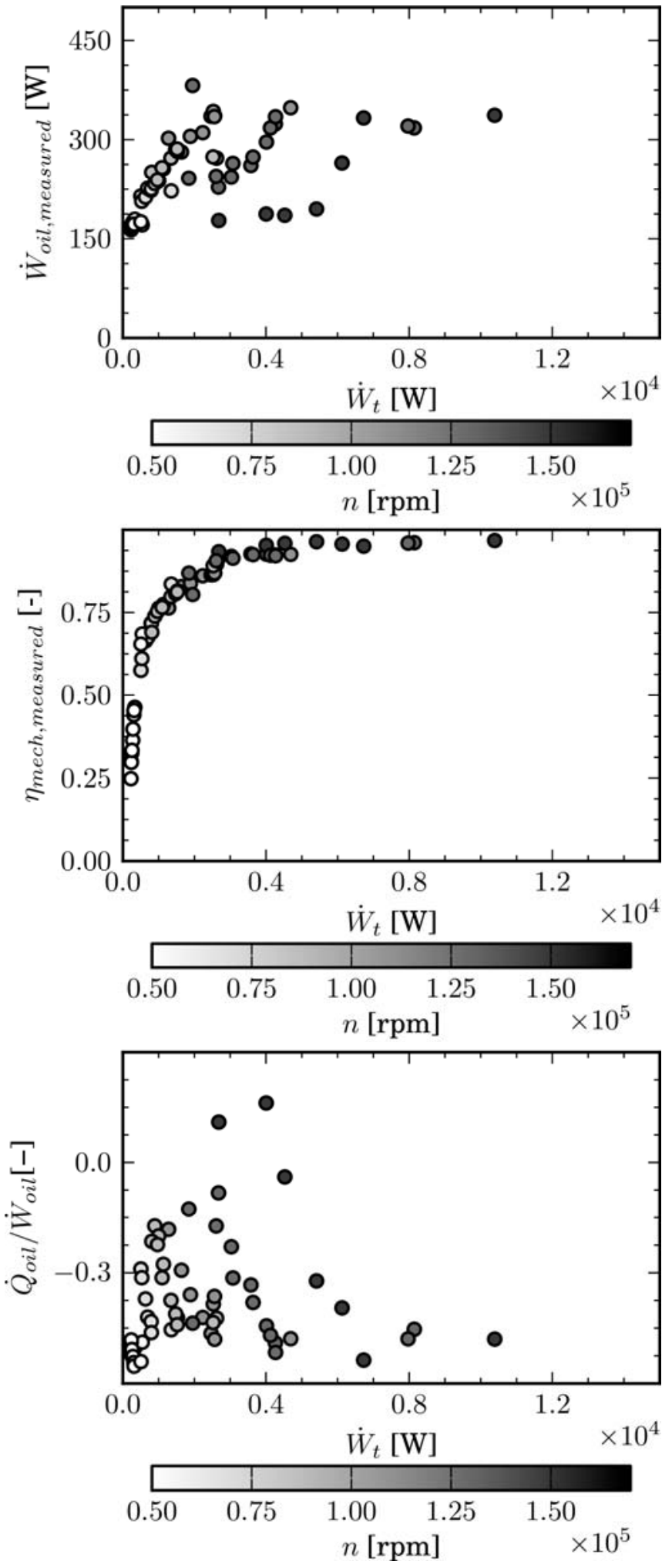

Figure 3. Second turbocharger, experimental results. 

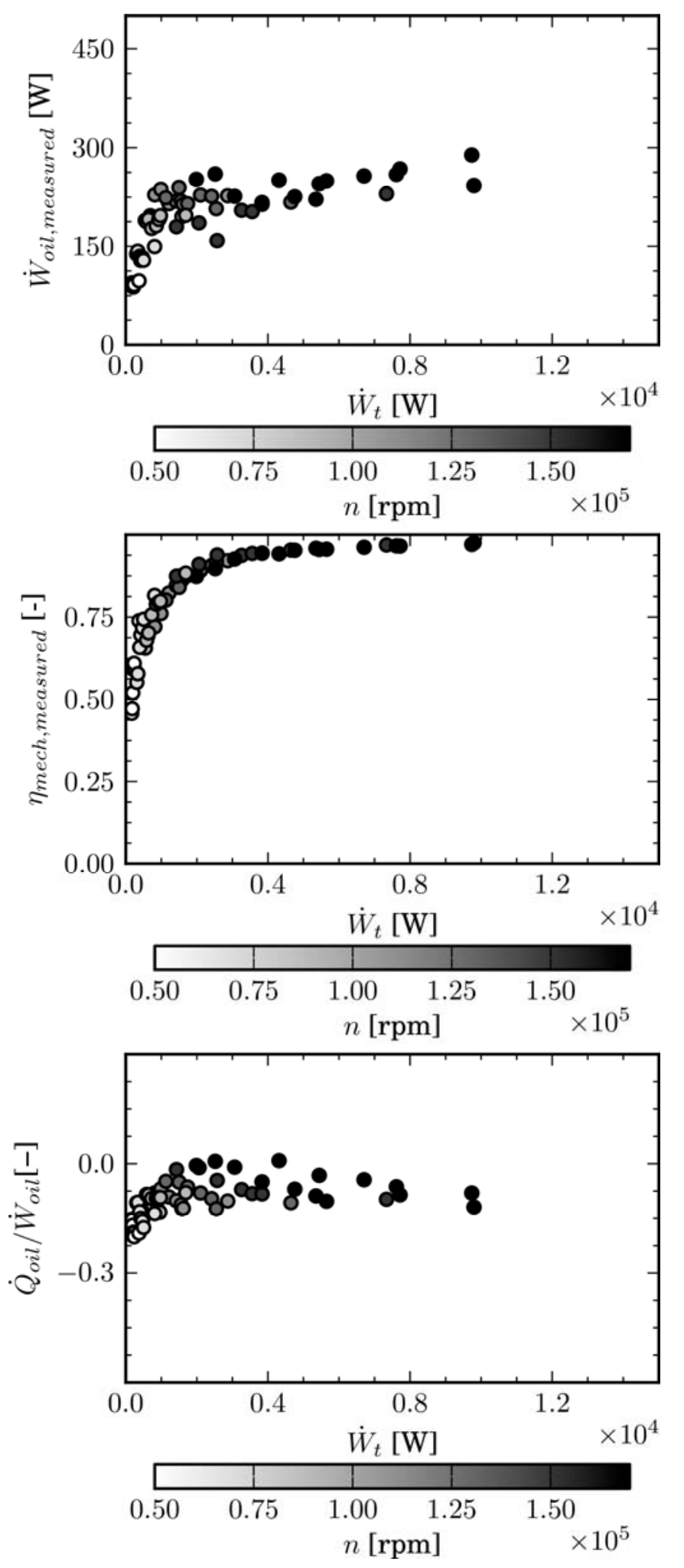

Figure 4. Third turbocharger, experimental results.

In figure 5 the model is adjusted to the first turbocharger experimental data. In the upper part of figure 5 , the continuous line represents perfect fit, the dashed line $\pm 25 \mathrm{~W}$ of error and

Page 5 of 10 the dash-dotted line $\pm 50 \mathrm{~W}$ of error. In the lower part of figure 5 , the continuous line represents perfect fit, the dashed line \pm 5 $\%$ of error and the dash-dotted line $\pm 10 \%$ of error. The model shows its greatest discrepancies in power at high turbocharger speeds. It can be explained due to high uncertainties in the enthalpy rise measurement between the inlet and outlet of the lubrication system due to low temperature changes when the turbocharger speed is high, to the uncertainties associated to the oil dynamic viscosity characterization at high temperatures and to the simplicity of the axial load used. Nevertheless, the greatest differences in power occur when the turbine output power is maximum, so the errors in mechanical efficiency are of small importance. At low rotational speeds, however, small errors in power of around $10 \mathrm{~W}$ incur in appreciable discrepancies between the measured and the modeled mechanical efficiency.

The second turbocharger results are shown in figure 6. As in the previous case, some discrepancies arise at high rotational speeds, when the oil temperature is high and its change between the inlet and the outlet of the lubrication system is minimum. Again, the observed discrepancies are of small importance observing the mechanical efficiency plots: when the turbine power output is very high, differences of $20 \%$ in predicted mechanical losses power are translated in differences in efficiency of between $1 \%$ and $2 \%$. Again, when the turbocharger is working at extremely low rotational speeds, the errors in mechanical efficiency are more important, but the turbocharger rarely works at these operating conditions.

The third and smaller tested turbocharger shows better results than the others. In this case, the error committed in power transmission losses is small in the whole tested operating conditions. The model shows good agreement with the experimental data even when working at low rotational speeds and mechanical efficiencies of around $50 \%$, with mechanical efficiency errors always below $\pm 5 \%$.

To demonstrate the need of a mechanical losses model, the testing campaign with steady flow conditions has been simulated using the aforementioned model, no mechanical losses and a fixed mechanical efficiency of $90 \%$. In the following graphics, the dimensionless error in simulated speed is plotted in absolute value against the turbine power. The condition of constant mechanical efficiency of $90 \%$ has been chosen as a typical used value during constant efficiency simulations.

Not using a mechanical losses model gives very high turbocharger speed errors in all the tested operating conditions. Assuming a constant mechanical efficiency of 90 $\%$ gives good results at high turbine powers, but fails at low powers. The best results are obtained by using the mechanical losses model, which takes into account the variation of power transmission losses between the turbine and the compressor in every operating point. 

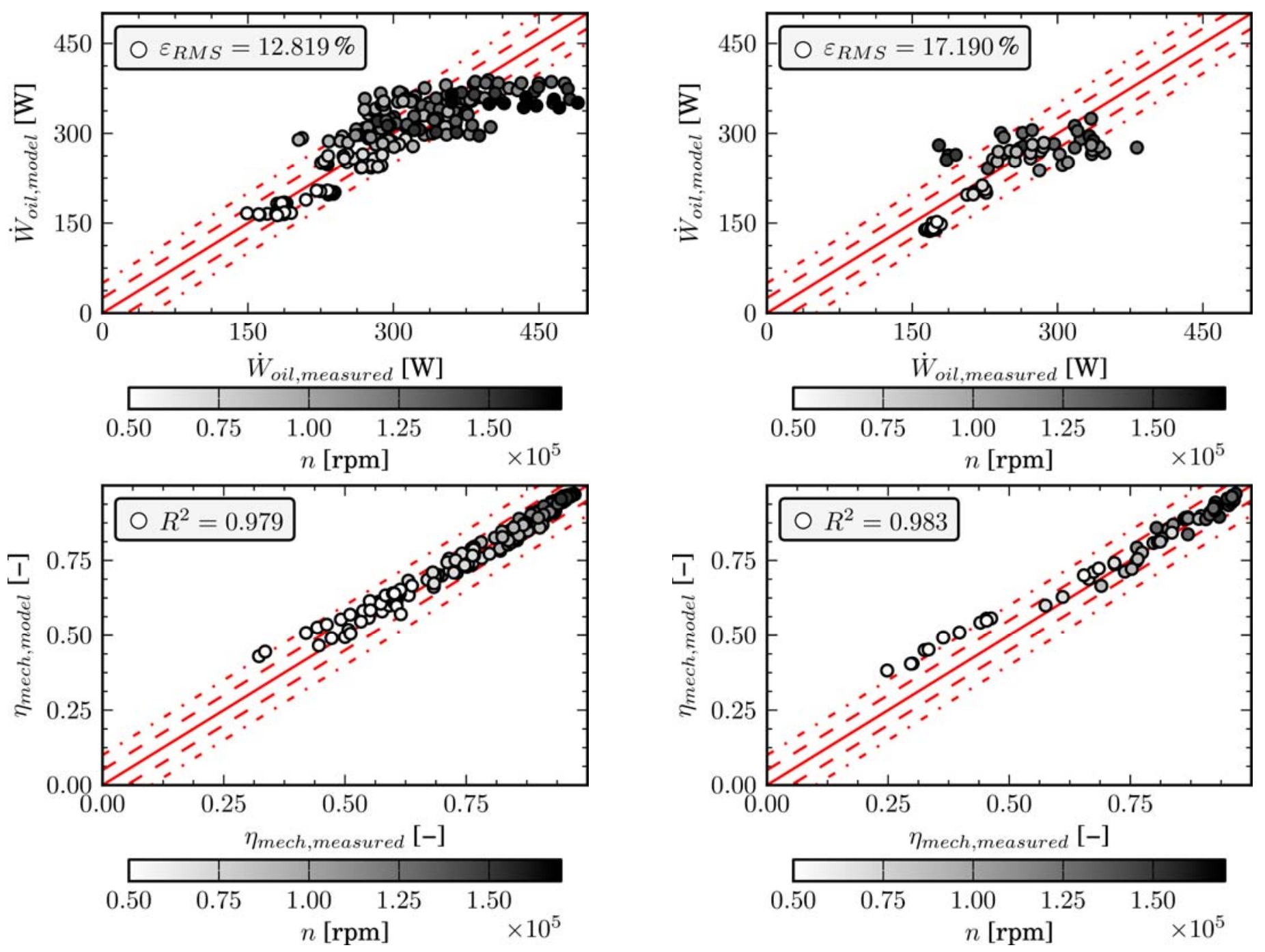

Figure 5. First turbocharger, stationary modeled results .

Figure 6. Second turbocharger, stationary model results. 

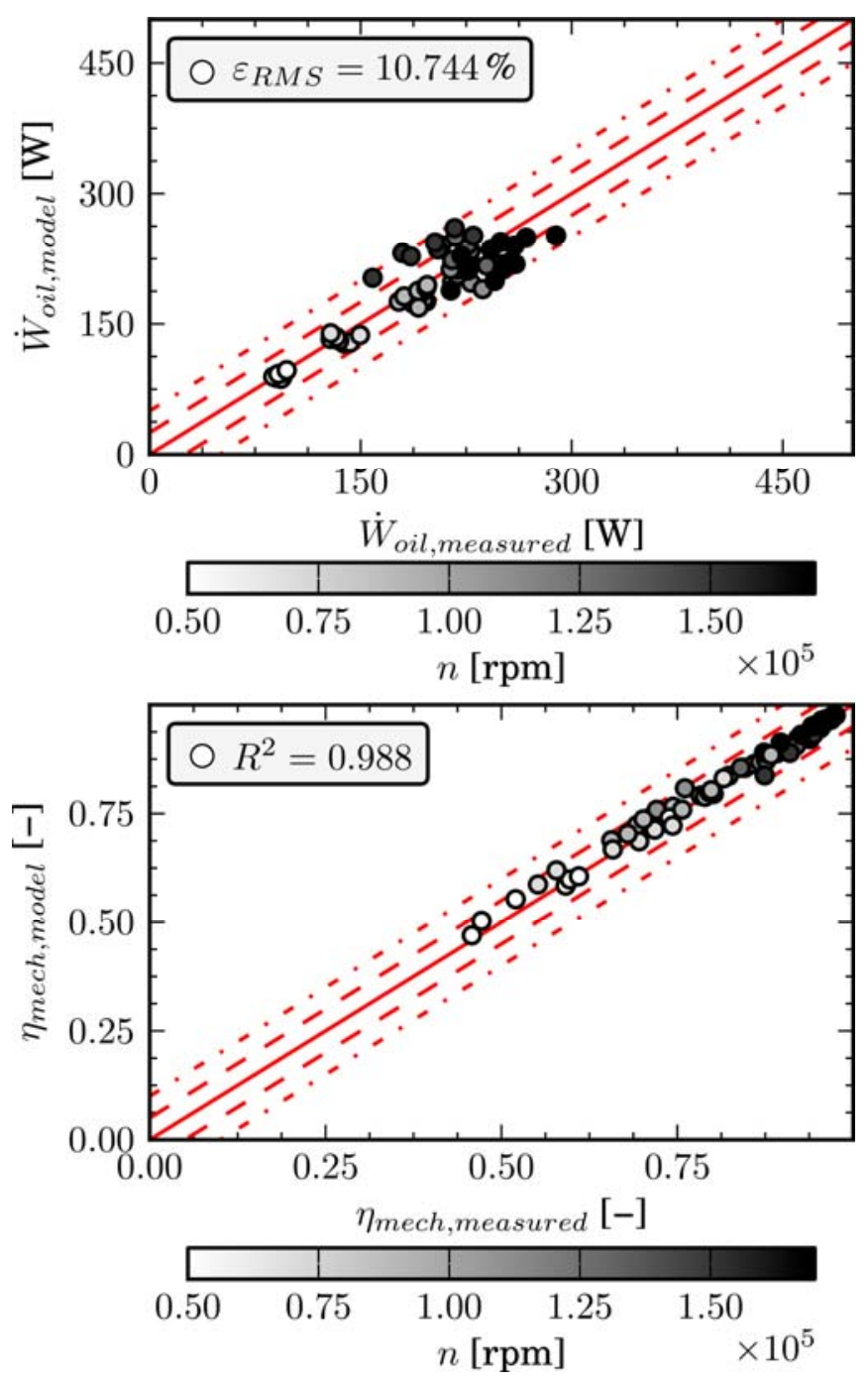

Figure 7. Third turbocharger, stationary model results.

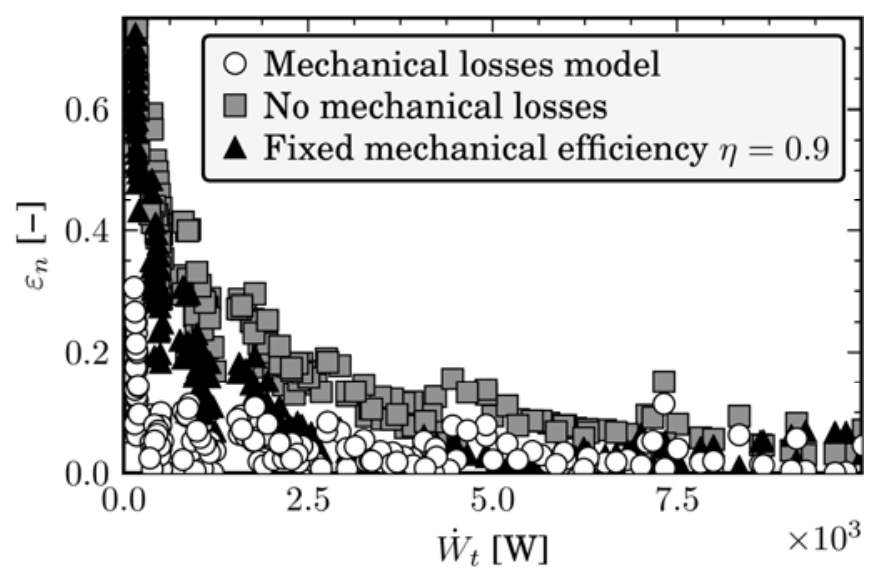

Figure 8. First turbocharger, simulated speed error.

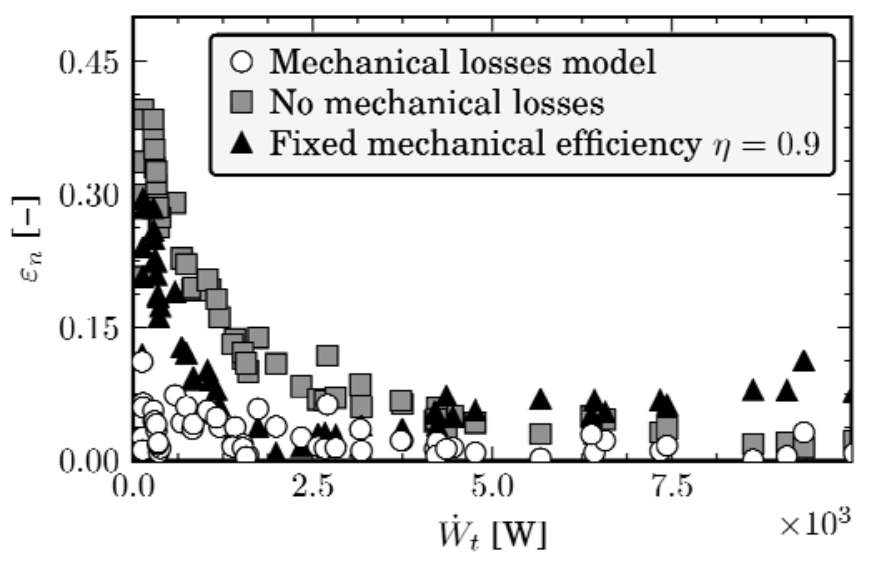

Figure 9. Second turbocharger, simulated speed error.

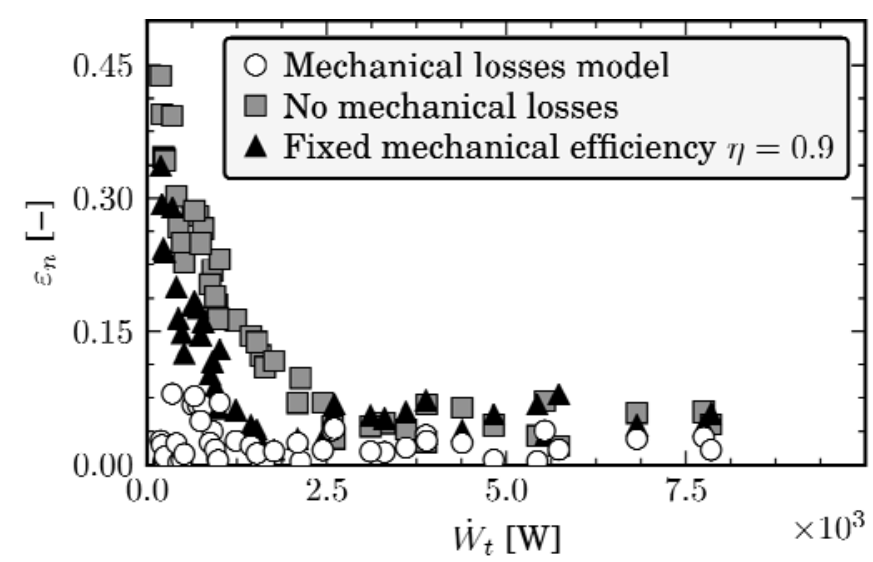

Figure 10. Third turbocharger, simulated speed error.

The models are further used with pulsating flow data from experiments done in the gas stand, simulating pulses of amplitude and frequency typically found in the exhaust manifold of diesel turbocharged engines with oil temperatures similar to that found in urban driving conditions:

In figure 11, results for pulsating flow at an engine speed of $2000 \mathrm{rpm}$ and an engine load of $12 \%$ of the maximum torque are presented for the first turbocharger. The upper graph of figure 11 shows in black the isentropic efficiency of the turbine, calculated with the model described in the work from Pairy et al. [20]; in gray solid line the mechanical efficiency; and in dash-dotted the product of both, plotted against the crank angle. As it can be seen, both mechanical and isentropic efficiency are unphased. It is clearer in the lower graphic of figure 11, where the efficiencies are plotted against the blade tip speed ratio: when the isentropic efficiency rises, the mechanical efficiency drops. The available power is the isentropic turbine power times the isentropic efficiency times the mechanical efficiency. 

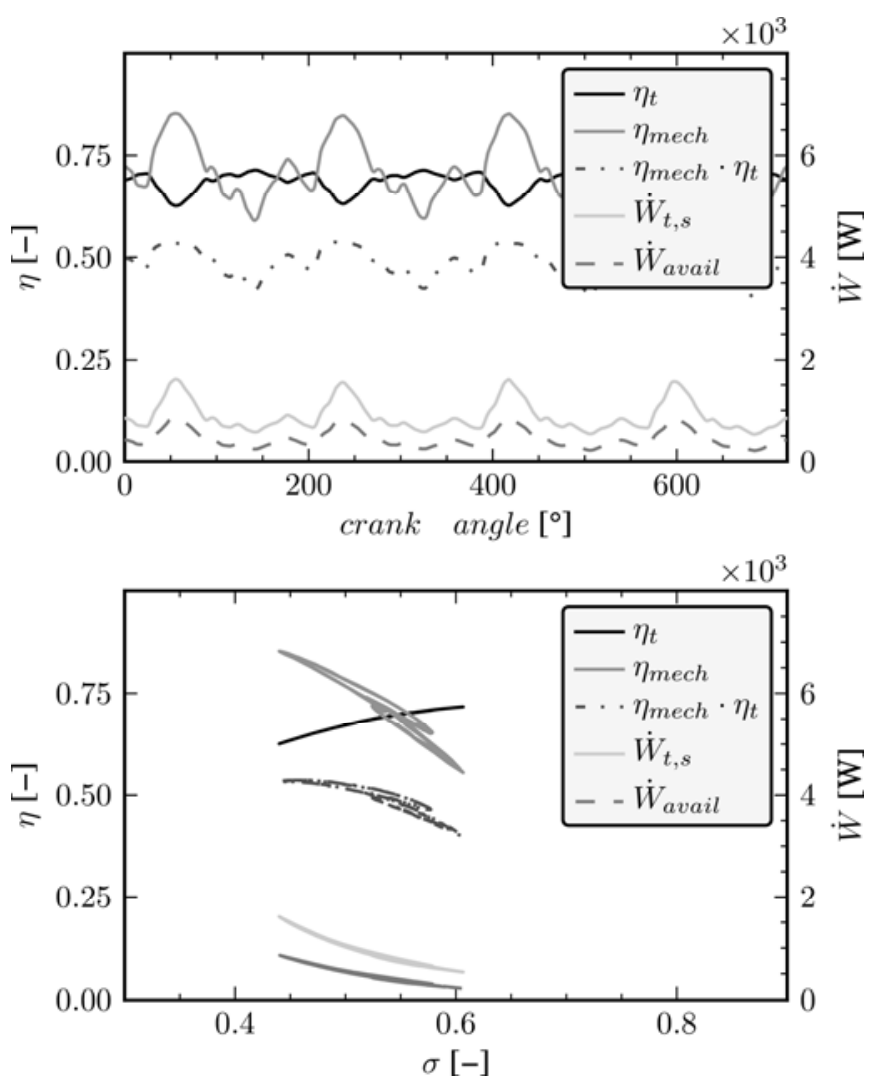

Figure 11. First turbocharger, 2000 rpm and $12 \%$ load.

In figure 12, results are shown for an engine speed of 2000 rpm and an engine load of $25 \%$ for the second turbocharger. This time, both mechanical and isentropic efficiency appears to be almost in phase, so the maximum of the product is near the maximum of the turbine maximum isentropic efficiency, which can be translated in maximum available power at the compressor side. The available power is a scaled-down and deformed version of the turbine isentropic power.

In figure 13, results are plotted for an engine speed of 2000 rpm and an engine load of $50 \%$ for the third turbocharger. Again, both mechanical and isentropic efficiencies are unphased. Nevertheless, in this case the product of both efficiencies is working near its maximum value during longer periods of time. As the minimum efficiencies happen at high blade tip to air speed ratio, its effect is minimized.
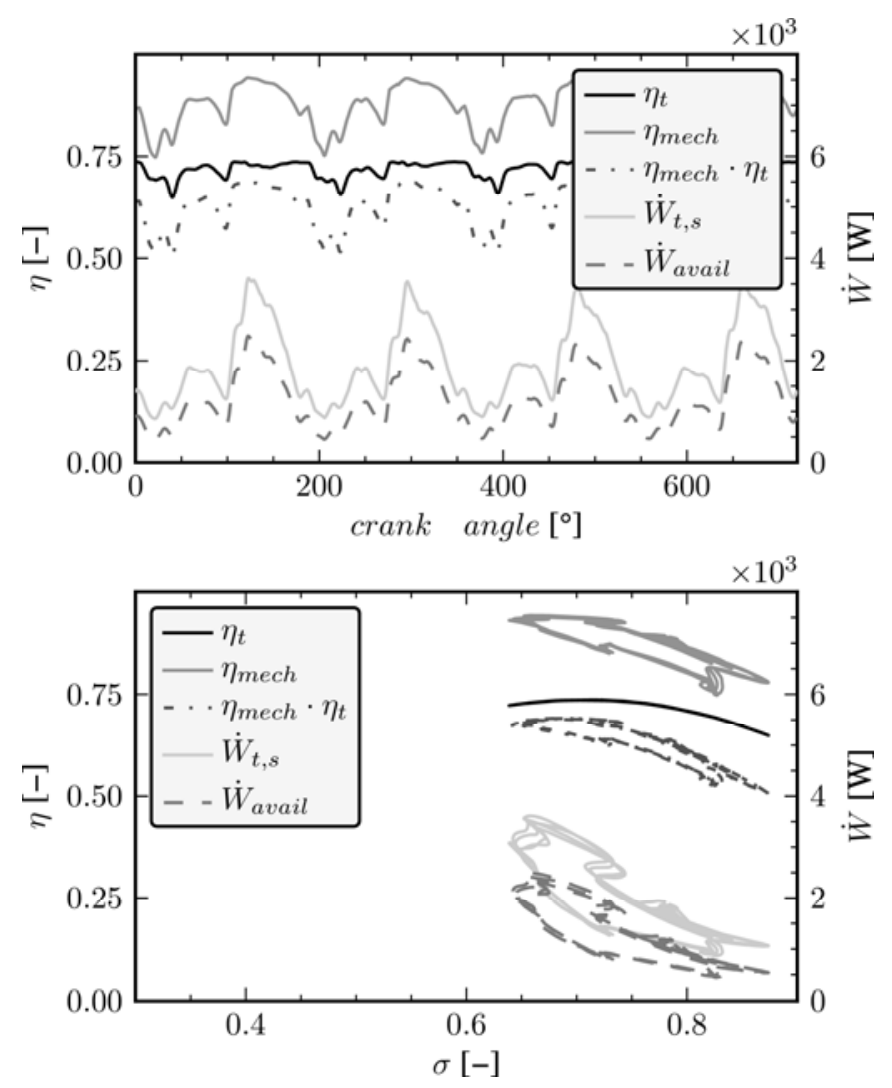

Figure 12. Second turbocharger, 2000 rpm and $25 \%$ load.

Table 4 shows the model error of the three operating points.

\begin{tabular}{|c|c|c|c|c|c|c|}
\hline $\begin{array}{c}\text { Engine } \\
\text { speed }\end{array}$ & $\begin{array}{c}\text { Engine } \\
\text { load }\end{array}$ & $n$ & $\dot{m}_{t}$ & $\dot{m}_{c}$ & $\pi_{t}$ & $\pi_{c}$ \\
\hline rpm & $\%$ & $\%$ & $\%$ & $\%$ & $\%$ & $\%$ \\
\hline 2000 & 12 & 1.7 & 0.5 & 1.9 & 0.1 & 0.1 \\
\hline 2000 & 25 & 4,5 & 0,9 & 4.8 & 0.1 & 2.1 \\
\hline 2000 & 50 & 0.1 & 3.4 & 0.0 & 0.9 & 1.7 \\
\hline
\end{tabular}

Table 4. Model error.

During pulsating flow, the mechanical efficiency of the turbocharger can instantaneously change between very high and very low values, due to variations in both power transmission losses and turbine power output. The model of power transmission loss can change instantaneously due to crank angle variations of axial loading, affecting axial thrust bearing power losses, as shown in equation (4). If a constant mechanical efficiency is used to model the turbocharger behavior, there will be bigger errors than when modeling its instantaneous variations. The mechanical efficiency times the isentropic turbine efficiency can change notably even when the turbine isentropic efficiency is almost constant due to changes in mechanical efficiency. The model also shows that the mechanical efficiency can have its minimum value at points of high or low isentropic turbine efficiency, depending on the operating conditions. 

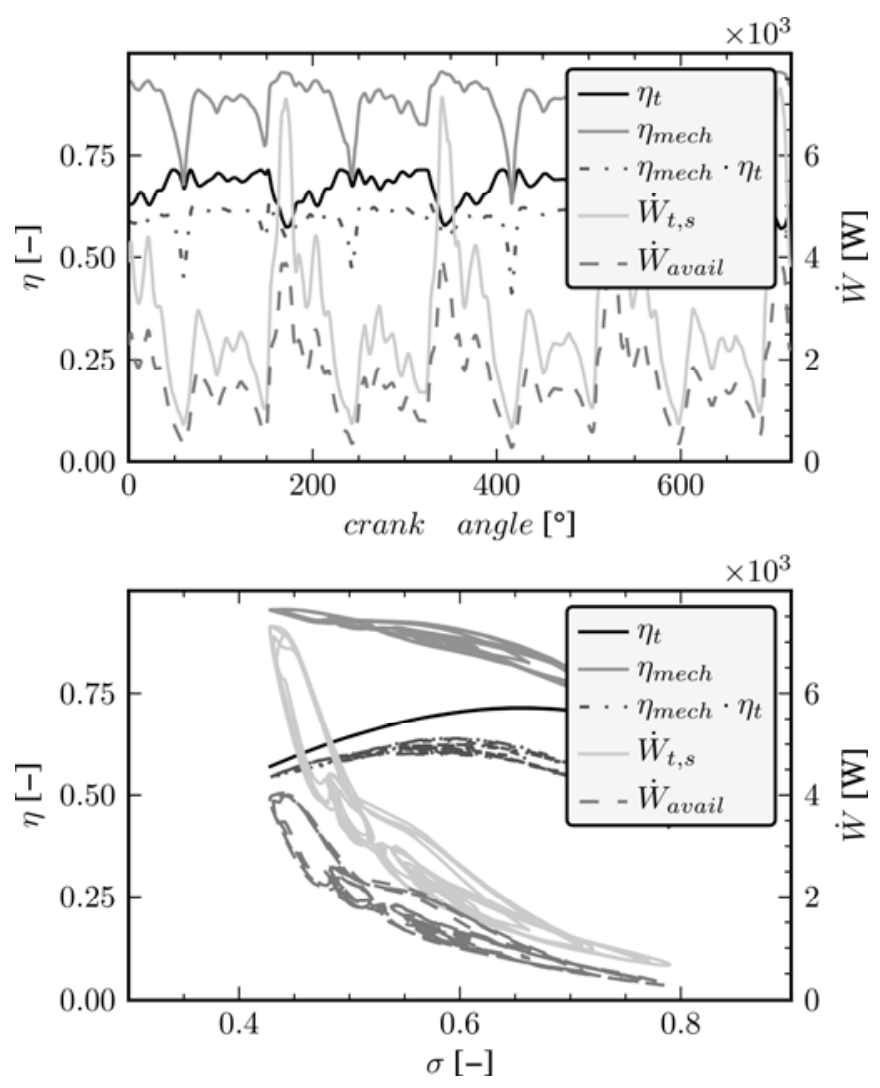

Figure 13. Third turbocharger, 2000 rpm and $50 \%$ load.

\section{SUMMARY/CONCLUSIONS}

Although typically high during highway driving conditions, mechanical efficiency of turbochargers becomes small during urban driving cycles, when oil temperature is relatively low.

With current downsizing trends, turbines tend to work under high amplitude pulsating flow, rendering its power output and mechanical losses far from constant even at steady engine operation. Non-linear effects make even more difficult to properly achieve good results during 0d-1d simulations of engines, so it is important to take into account the instantaneous variation of both turbine power output and mechanical losses to get better results. The model used in the present work gives some insight about the instantaneous evolution of mechanical efficiency during pulsating flow conditions, showing that, at low to medium engine operating points, it can vary greatly during an engine cycle.

When simulating highly variable turbocharger conditions the constant mechanical efficiency computations show weakness, underestimating the available power at the compressor side at high rotational speeds or overestimating it at low rotational speeds. If only very high turbine powers will be simulated, a constant mechanical efficiency should give accurate results. Therefore, the authors of the present work recommend using a turbocharger model during 1D simulation that can compute instantaneous mechanical efficiency in a wide range of operating conditions such as the one presented here in realworld driving cycles. It is also advisable to accurately characterize the mechanical losses behavior in low to medium engine operating powers using specific experimental procedures such as using quasi-adiabatic tests in a cold gas stand or a torquemeter attached to the turbocharger.

\section{REFERENCES}

1. EEC, "Regulation (ec) no 595/2009 of the european parliament and of the council”, Official Journal of the European Communities, 2009.

2. N. Baines, "Fundamentals of Turbocharging", Concepts NREC, 2005.

3. A. Diango, C. Perilhon, G. Descombes, and E. Danho, "Application of exergy balances for the optimization of non-adiabatic small turbomachines operation”, Energy, vol. 36, pp. 2924-2936, May 2011.

4. M. Deligant, P. Podevin, and G. Descombes, "Cfd model for turbocharger journal bearing performances”, Applied Thermal Engineering, vol. 31, pp. 811-819, 2011.

5. L. Lihua, S. Hao, and L. Y. Z. Qiang, "Research on static stiffness of hydrostatic bearing using fluid-structure interaction analysis”, Procedia Engineering, vol. 29, pp. 1304-1308, 2012.

6. W. J. Chen, "Rotordynamics and bearing design of turbochargers", Mechanical Systems and Signal Processing, vol. 29, pp. 77-89, May 2012.

7. S. Shaaban, "Experimental Investigation and Extended Simulation of Turbocharger Non-Adiabatic Performance", PhD thesis, Universitt Hannover, Fachbereich Maschinenbau, 2004.

8. P. Podevin, A. Clenci, and G. Descombes, "Influence of the lubricating oil pressure and temperature on the performance at low speeds of a centrifugal compressor for an automotive engine”, Applied Thermal Engineering, vol. 31, no. 2-3, pp. 194 - 201, 2011.

9. F. Payri, J.R. Serrano, P. Olmeda, A. Páez, and F. Vidal, "Experimental methodology to characterize mechanical losses in small turbochargers”, ASME Conference Proceedings, vol. 2010, no. 44007, pp. 413-423, 2010.

10. L. Hu, C. Yang, H. Sun, E. Krivizky, L. Larosiliere, J. Zhang, and M. Lai, "Experimental and computational analysis of impact of self recirculation casing treatment on turbocharger compressor", SAE Technical papers, pp. 2010-01-1224, 2010.

11. M. Deligant, P. Podevin, and G. Descombes, "Experimental identification of turbocharger mechanical friction losses”, Energy, vol. 39, pp. 388-394, Mars 2012.

12. J.R. Serrano, P. Olmeda, A. Páez and F. Vidal, "An Experimental Procedure to Determine Heat Transfer Properties of Turbochargers”, Measurement Science and Technology, 21, 2010.

13. "Turbocharger gas stand code", S. of Automotive Engineers Inc, 1995.

Page 9 of 10 
14. Luján, J., Bermúdez, V., Serrano, J.R. and Cervelló, C., "Test bench for turbocharger groups characterization", SAE International, 2002.

15. Serrano, J.R., Arnau, F.J., Fajardo, P. and ReyesBelmonte, M.A., "Contribution to the Modeling and Understanding of Cold Pulsating Flow Influence in the Efficiency of Small Radial Turbines for Turbochargers”, Journal of Engineering for Gas Turbines and Power, October 2012.

16. Serrano, J.R., Olmeda, P., Arnau, F., Reyes-Belmonte, M.A. and Lefebre, A.., "Importance of heat transfer phenomena in small turbochargers for passenger car applications”, SAE Technical paper, 2013.

17. OpenWAM website, CMT-Motores Térmicos (Universitat Politècnica de València), http://www.openwam.org/, 2012.

18. Galindo, J., Serrano, J.R., Arnau, F.J. and Piqueras, P., "Description of a semi-independent time discretization methodology for a one-dimensional gas dynamics model, J Eng Gas Turbines Power 2009, 131:034504.

19. Serrano, J.R., Olmeda, P., Tiseira, A., García-Cuevas, Luis Miguel and Lefebvre, A., "Theoretical and Experimental Study of Mechanical Losses in Automotive Turbochargers", submitted to Energy.

20. Payri, F., Serrano, J.R., Fajardo, P., Reyes-Belmonte, M.A. and Gonzalo-Belles, R., "A physically based methodology to extrapolate performance maps of radial turbines”, Energy Conversion and Management, 2012, 55, 149-163

\section{CONTACT INFORMATION}

Prof. J.R. Serrano jrserran@mot.upv.es, +34963879657.

\section{ACKNOWLEDGMENTS}

The authors of this paper wish to thank M.A. Ortiz and V. Ucedo for their invaluable work during the experimental setup and campaign, F.J. Arnau, Ph.D, for its excellent job maintaining and expanding OpenWAM's code base and M.A. Reyes-Belmonte for all his hard and rigorous work extrapolating turbine maps and preparing and launching the simulations.

\section{DEFINITIONS/ABBREVIATIONS}

\begin{tabular}{|c|c|}
\hline VGT & variable geometry turbine \\
\hline$T$ & temperature \\
\hline$\dot{m}$ & mass flow rate \\
\hline$p$ & pressure \\
\hline$n$ & turbocharger speed \\
\hline C & specific heat capacity \\
\hline oil & oil \\
\hline$t$ & turbine \\
\hline C & compressor \\
\hline in & inlet \\
\hline out & outlet \\
\hline $\min$ & minimum \\
\hline $\max$ & maximum \\
\hline$R$ & radius \\
\hline$L$ & length \\
\hline$A$ & area \\
\hline mean & mean \\
\hline mech & mechanical \\
\hline$\mu$ & oil dynamic viscosity \\
\hline$\eta$ & efficiency \\
\hline measured & measured \\
\hline model & modelled \\
\hline$\dot{W}$ & power \\
\hline$\dot{Q}$ & heat flow \\
\hline$k$ & fitting parametter \\
\hline$G$ & geometry parameter \\
\hline$\sigma$ & blade tip to air speed ratio \\
\hline$b$ & backplate \\
\hline$j b$ & journal bearing \\
\hline$t b$ & thrust bearing \\
\hline$h$ & oil film thickness \\
\hline
\end{tabular}

